\title{
ASPECTOS MORFOLÓGICOS DO FRUTO, DA SEMENTE E DESENVOLVIMENTO PÓS-SEMINAL DE FAVEIRA (Clitoria fairchildiana R. A. Howard. - FABACEAE) ${ }^{1}$
}

\author{
BRENO MARQUES DA SILVA E SILVA²; FABIOLA VITTI MÔRO³
}

\begin{abstract}
RESUMO - O presente trabalho teve por objetivo descrever a morfologia dos frutos, das sementes e o desenvolvimento pós-seminal de faveira (Clitoria fairchildiana R. A. Howard. - Fabaceae). Os frutos e as sementes foram caracterizados quanto à forma e dimensões. Periodicamente, unidades representativas de cada fase de germinação foram retiradas para as descrições morfológicas. Os frutos são do tipo legume, deiscentes e de coloração marrom. As sementes são exalbuminosas, de forma orbicular e achatada, com tegumento de coloração castanho-esverdeada. O hilo tem forma elíptica, homocromo e de tamanho pequeno em relação à semente. Os cotilédones são livres, de coloração verde, maciços e plano-convexos e o embrião é invaginado. O início do desenvolvimento pósseminal é marcado pelo rompimento do tegumento e emissão da raiz primária, glabra, de coloração amarelo-esverdeada e de forma cilíndrica. Posteriormente, observa-se o desenvolvimento das raízes secundárias, levemente esbranquiçadas, curtas e filiformes. Em seguida, o crescimento do hipocótilo proporciona a emergência dos cotilédones e da plúmula acima do substrato. O epicótilo alonga-se e, em seguida, observa-se a expansão dos eófilos, simples, opostos, com tricomas simples e esparsos, pecíolos curtos com estípulas em sua base. Posteriormente ao desenvolvimento dos eófilos, ocorre a formação do segundo par de folhas, alternas, trifolioladas, estipuladas e com estipelas na base dos peciólulos.
\end{abstract}

Termos para Indexação: biometria, caracterização morfológica, análise de sementes, germinação.

\section{MORFOLOGICAL ASPECTS OF THE FRUIT, SEED AND POST-SEMINAL DEVELOPMENT OF FAVEIRA (Clitoria fairchildiana R. A. Howard - FABACEAE)}

\begin{abstract}
The present work aimed to describe the morphology of the fruits, seeds and the postseminal development of faveira (Clitoria fairchildiana R. A. Howard. - Fabaceae). The fruits and the seeds were characterized as its form and dimensions. Periodically, representative units of each germination phase had been removed for the morphological descriptions. The fruits are dehiscent legume of brown coloration. The seeds are unalbuminous, of flattened orbicular form, with a chestnutgreen tegument. The hilum is elliptical, homochromus and of small size in relation to the seed. The
\end{abstract}

\footnotetext{
${ }^{1}$ Submetido em 14/09/2006. Aceito para publicação em 30/07/2007.

${ }^{2}$ Biólogo. Bolsista de Mestrado do CNPq - Mestrando em Agronomia [Produção e Tecnologia de Sementes] da Universidade Estadual Paulista/ UNESP - Faculdade de Ciências Agrárias e Veterinárias/FCAV Departamento de Produção Vegetal/DPV - Via de Acesso Prof. Paulo Donato Castellane s/n14884-900 Jaboticabal SP.
}

E-mail: silvabms@fcav.unesp.br

${ }^{3}$ Eng. Agra, Dra., Depto. De Biologia Aplicada à Agropecuária- UNESP/ FCAV- Via de Acesso Prof. Paulo Donato Castellane s/n14884-900 Jaboticabal - SP Bolsista de Produtividade do CNPq . E-mail: fabiola@, fcav.unesp.br (autor para correspondência) 
cotyledons are free, of green coloration, plan-flattened, bulks and the embryo is invaginated. The beginning of the post-seminal development is marked by the disruption of the tegument and emission of the primary root, glabrous and cylindrical of yellow-green coloration. Later, the development of the secondary roots is observed, lightly white, filiforms and shortness. After that, the growth of hipocotyl provides the emergency of the cotyledons and plumule. The epicotyl elongates and often is observed eophylum expansion, which are simple, opposite, with simple and dispersed tricomes, short petioles, with stipules in the base. Often the development of the eophylum, it occurs the formation of the second pair of leaves, alternating, trifoliolate, with stipels in the base of the footstalks.

Index terms: biometry, morphological characterization, seed technology

\section{INTRODUÇÃO}

As Fabaceas possuem amplo destaque nos mais diversos ecossistemas amazônicos, sendo a mais importante família de plantas dentre as lenhosas (Ducke e Black, 1953). Papilionoideae, a maior subfamília de Fabaceas, está representada por aproximadamente 10.000 espécies e cerca de 500 gêneros (Ribeiro et al., 1999), sendo o gênero Clitoria L. detentor de mais ou menos 40 espécies nos países tropicais e subtropicais, destacando-se como arbóreas, arbustivas ou herbáceas, erectas ou volúveis, com predomínio das últimas na hiléia, de flores róseas, brancas ou violáceas (Ducke, 1949).

Clitoria fairchildinana, sinonímia C. racemosa Lindl. (Lorenzi, 1992), popularmente conhecida como faveira, sombreiro ou palheteira é uma espécie arbórea de médio a grande porte, com frondosa copa e flores atrovioláceas em rácemos pêndulos e fruto um legume deiscente. Ocorre principalmente na Floresta Ombrófila Densa na Amazônia, em formações secundárias e apresenta nítida preferência por solos férteis e úmidos, podendo também ocorrer em áreas abertas e alteradas (Ducke, 1949; Lorenzi, 1992).

A faveira, por possuir madeira moderadamente pesada e de média resistência, é empregada em construção civil como divisórias de casas, forros, para confecção de brinquedos e caixotaria, além de proporcionar ótima sombra e apresentar características ornamentais, tornando-se assim, excelente, para arborização rural e urbana de parques jardins, estradas, dentre outros (Paula e Alves, 1997; Guajará et al., 2003). Por ser uma espécie rústica e de rápido crescimento, é extremamente útil nos reflorestamentos heterogêneos destinados à reconstituição da vegetação e recuperação de áreas degradadas (Lorenzi, 1992; Portela et al., 2001). Além disso, a faveira possui potencial para cobertura de áreas degradadas atuando como adubo verde, pois é capaz de nodular e fixar nitrogênio (Carneiro et al., 1998; Fortes,
2000).

A realização crescente de plantações para recuperação ambiental requer o desenvolvimento de conhecimentos sobre tecnologia de sementes de árvores brasileiras, para que os lotes sejam aproveitados de modo racional (Zanon et al., 1997).

De acordo com Oliveira e Pereira (1984), Groth e Liberal (1988) e Barroso (1999), tanto as características externas quanto as internas das sementes são pouco modificadas pelo ambiente, constituindo-se em um critério bastante seguro para a identificação de famílias, gêneros e, às vezes, espécies. No entanto, poucos manuais e trabalhos são específicos para identificação e, na maioria deles, a morfologia de sementes é ignorada ou recebe tratamento secundário, sendo, portanto, inadequados, pois as sementes são conservativas na sua morfologia e freqüentemente evidenciam caracteres familiares (Gunn, 1981, Oliveira, 1993).

Segundo Kuniyoshi (1983) e Feliciano (1989), a identificação botânica de sementes se faz necessária em manejo, em conservação da fauna silvestre (estudo de conteúdo estomacal em aves e outros herbívoros), em estudos ecológicos, em paleobotânica e em arqueologia.

Nos estudos de sucessão e regeneração em ecossistemas florestais, os caracteres morfológicos e anatômicos são fundamentais para avaliar, identificar e separar as espécies do banco de sementes, assim como, do banco de plântulas (Pinheiro et al., 1989). Igualmente, a morfologia interna e externa da semente, aliada às observações das plântulas, permitem fazer a identificação das estruturas, oferecendo, em laboratório, subsídios à interpretação correta dos testes de germinação, identificação e certificação da qualidade fisiológica. Assim, podeauxiliarosestudos dearmazenamento, e, no viveiro, contribui para o reconhecimento da espécie e para adequar os métodos de produção de mudas para diversos fins (Araújo e Matos, 1991; Oliveira, 1993; Amorin et al., 1997). Neste sentido, mais recentemente Oliveira 
(1999) apresentou características morfológicas de plântulas e plantas jovens de 30 espécies arbóreas de Leguminosae, visando contribuir em estudos taxonômicos ou ecológicos de regeneração de áreas degradadas.

Desta forma, o presente trabalho teve por objetivo caracterizar morfo-biometricamente o fruto, a semente e descrever o desenvolvimento pós-seminal de faveira (Clitoria fairchildiana).

\section{MATERIAL E MÉTODOS}

Em Agosto de 2005, foram coletados frutos de matrizes de Clitoria fairchildiana localizadas no Campus da Faculdade de Ciências Agrárias e Veterinárias/FCAV - Universidade Estadual Paulista/UNESP Campus da UNESP, Jaboticabal - SP - Brasil.

Para a descrição e biometria dos frutos, das sementes e plântulas, o material foi examinado a fresco e as medições foram efetuadas aleatoriamente em amostras de 50, $100 \mathrm{e}$ 25 unidades, respectivamente, com o auxílio de paquímetro digital e régua milimetrada. Para as sementes, foram tomadas as medidas mínimas e máximas de comprimento, largura e espessura. Para as plântulas, foram medidas a altura e espessura do colo, bem como foram determinadas as respectivas massas de matéria seca, por meio da secagem em estufa a $70^{\circ} \mathrm{C}$ durante 72 horas (Benincasa, 1998). Determinou-se o número de sementes/fruto, o peso de 1000 sementes e o número de sementes/kg (Brasil, 1992).

Os frutos foram caracterizadosquanto a: tipo, consistência, superfície, indumentos, forma, deiscência, coloração, ápice, margens e base (Damião-Filho, 1993; Barroso et al., 1999; Damião-Filho e Môro, 2005).

Para as sementes, foram observadas as características: forma, coloração, textura, presença ou ausência do endosperma, forma, tipo e posição do embrião (DamiãoFilho, 1993; Barroso et al., 1999; Damião-Filho e Môro, 2005).

Para a descrição do processo germinativo e das plântulas, 100 sementes foram colocadas para germinar em bandejas, com areia lavada e esterilizada, umedecida com solução aquosa de Nistatina $0,2 \%$, mantidas em casa de vegetação, sob sombreamento de $50 \%$ e temperatura de $22,2^{\circ} \mathrm{C} \pm 5,06$. Diariamente, foram realizadas observações para descrição dos diversos estádios da germinação, coletando-se amostras das plântulas em fases seqüenciais de desenvolvimento, evidenciando-se: o desenvolvimento da raiz primária, o surgimento de raízes secundárias e a emergência dos cotilédones, o início do crescimento da primeira folha e da gema apical conspícua, a expansão do primeiro e segundo pares de folhas. A germinação foi caracterizada quanto ao tipo e, as plântulas, quanto à forma, coloração, textura, indumentos, superfície e venação dos protófilos e da folha, filotaxia e presença ou ausência de apêndices (Ribeiro et al., 1999; Damião-Filho, 1993; Damião-Filho e Môro, 2005).

Posteriormente, foram elaboradas as ilustrações dos frutos, das sementes, das fases da germinação e das plântulas, com o auxílio de estereomicroscópio com câmara clara. De forma geral, as descrições seguiram os critérios e as terminologias adotados por Duke (1969), Corner (1976), Feliciano (1989), Oliveira (1993), Damião-Filho (1993), Barroso et al. (1984), Barroso et al. (1999) e Damião-Filho e Môro (2005).

\section{RESULTADOS E DISCUSSÃO}

Descrição dos frutos: O número de sementes/fruto é de $9,7 \pm 2,5$ sementes (Figura 1). De acordo com o comprimento, largura e espessura, a maior freqüência de frutos está entre as medidas de 25 a $30,2,6$ a 2,9 e 0,7 a $0,9 \mathrm{~cm}$, respectivamente, enquanto, as respectivas dimensões máximas/mínimas variaram de $12,4 / 30,9 ; 2,2 / 3,2$ e $0,5 / 0,9 \mathrm{~cm}$, sendo que suas médias e respectivos desvios padrões foram $25,6 \pm 4,1$; $2,8 \pm 0,1$ e $0,7 \pm 0,1 \mathrm{~cm}$. De forma geral, para os parâmetros avaliados, a curva de freqüência entre as faixas de 0 a 34 $\mathrm{cm}$ segue uma distribuição normal (Figura 1). Resultados semelhantes foram obtidos por Oliveira et al. (2000) e Cruz et al. (2001) para os frutos de Tephrosia candida DC. e Hymenaea intermedia Ducke.

O fruto de faveira é um legume não articulado, deiscente, levemente curvo, seco e de coloração castanha na maturidade, com falsos septos transversais, glabro, longo, com abrupto afilamento em direção às extremidades, margens não constritas e placentação marginal (Figura 2). De forma semelhante, Barroso et al. $(1984 ; 1999)$ relatam a forma geral do fruto para o gênero Clitoria.

Descrição das sementes: $O$ peso de 1000 sementes, o número de semente/kg e teor de água das sementes de faveira foram $390,1 \mathrm{~g} \pm 7,4 ; 2097,2 \pm 501,9$ e $18,2 \% \pm 0,9$, respectivamente. De acordo com o comprimento, largura e espessura, a maior freqüência de sementes está compreendida nas dimensões de 12 a 15,12 a 15 e 2 a $3,5 \mathrm{~mm}$, respectivamente (Figura 1). As respectivas dimensões máximas e mínimas são de 9,5 e 16,5; 10,0 e 19,0 e 1,0 e 4,5mm, sendo que as médias e os respectivos desvios padrões são $13,4 \pm 1,3 ; 14,2 \pm 1,6$ e $3 \pm 0,4 \mathrm{~mm}$ (Figura 1). 


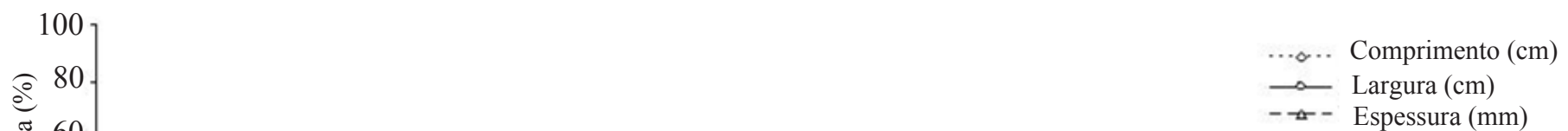

A
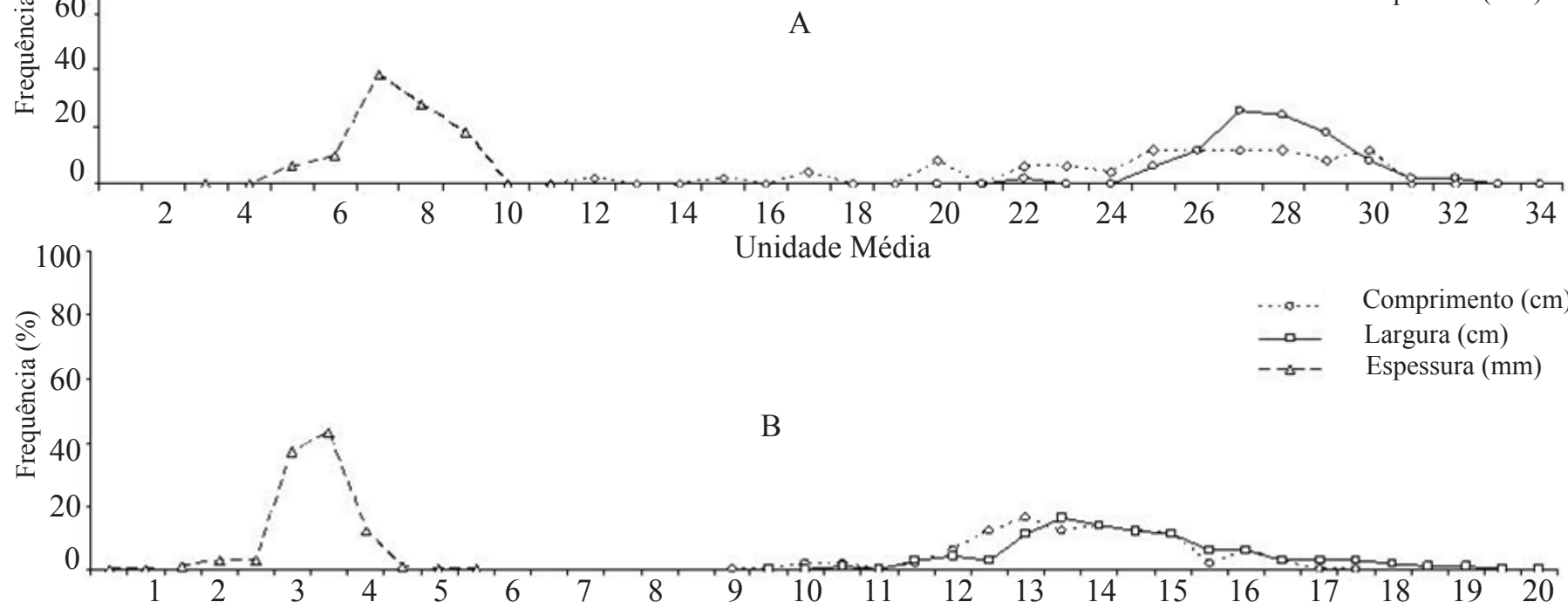
O tegumento é levemente rugoso, delgado e brilhante, de coloração castanho-esverdeada e com leve depressão na região hilar (fenda hilar), que segundo Barroso et al. (1984), é típica da sub-família Faboideae. O hilo se localiza na porção mediana da semente, tem forma elíptico-oblonga, é homocromo e de tamanho pequeno em relação à semente. Nota-se ainda, a presença de vestígios do funículo. Os dois cotilédones são livres, de coloração verde-clara, amiláceos, maciços e plano-convexos (Figura 3).

O embrião é invaginado, papilionáceo, sendo o eixo embrionário quase totalmente encoberto pelos cotilédones, não infletido, com plúmula conspícua, cuneiforme e eixo hipocótilo-radicular cônico e relativamente diferenciado (Figura 3). Segundo Corner (1976) e Damião-Filho (1993), o formato papilionáceo do embrião é característico da família Fabaceae. De acordo com ilustrações de Barroso et al. (1999), o eixo embrionário de Clitoria falcata Lam é infletido.

O embrião papilionáceo, geralmente, apresenta-se com cotilédones planos-convexos, variando de membranáceos a carnosos, com a inserção do eixo hipocótilo-radícula bem delimitada e de forma geralmente cordada-sagitada ou apenas profundamente sagitada (Barroso et al., 1999). O eixo pode estar parcialmente ou totalmente alojado entre os cotilédones, sendo nas Faboideae típicas, bastante curvo e infletido sobre os cotilédones. Porém, esta característica não é constante nessa subfamília, uma vez que o grau de inflexão é muito variável e o eixo pode ser reto (Corner, 1976; Barroso et al., 1999). Sabendo-se da influência que a forma do óvulo exerce na semente, Corner (1976) verificou que as sementes das Faboideae originam-se de óvulos campilótropos.

Descrição da germinação e da plântula: Aos 30 dias após a semeadura, a altura, a espessura do colo, a massa seca da raiz, do caule e das folhas, a razão de área foliar, a razão parte aérea/raiz, a razão altura/espessura do colo e a área foliar específica de plântulas de faveira foram, respectivamente, $17,2 \mathrm{~cm} \pm 2,77 ; 0,35 \mathrm{~mm} \pm 0,04 ; 0,1526 \mathrm{~g} \pm 0,06 ; 0,1631 \mathrm{~g} \pm$ 0,$09 ; 0,3367 \mathrm{~g} \pm 0,11 ; 116,19 \mathrm{~cm}^{2} \pm 3,99 ; 3,2559 \mathrm{~g} / \mathrm{g} \pm 0,96$; $47,14 \mathrm{~cm} / \mathrm{mm} \pm 5,99$ e $227,10 \mathrm{~cm}^{2} / \mathrm{g} \pm 44,35$.

A germinação de faveira é fanerocotiledonar epígea, iniciando-se no terceiro dia após a semeadura, com a protrusão da raiz primária, seguida de emergência dos cotilédones, da plúmula e formação da plântula, aos 7, 18 e 26 dias, respectivamente (Figura 4). Segundo Duke (1969), as plântulas fanerocotiledonares são aquelas em que os cotilédones libertam-se do tegumento da semente, após a germinação.

A fase inicial do desenvolvimento pós-seminal é marcada pelo rompimento do tegumento da semente e pela protrusão da raiz primária, glabra, de coloração amarelo-esverdeada e de forma cilíndrica (Figura 4). Quando a raiz primária atinge cerca de $2,4 \mathrm{~cm}$, pode ser observado o desenvolvimento das raízes secundárias, levemente esbranquiçadas, curtas e filiformes. Posteriormente, o crescimento do hipocótilo, cilíndrico e verde-claro, proporciona a emergência dos dois cotilédones, livres, maciços e de coloração verde-clara, e da plúmula (Figura 4).
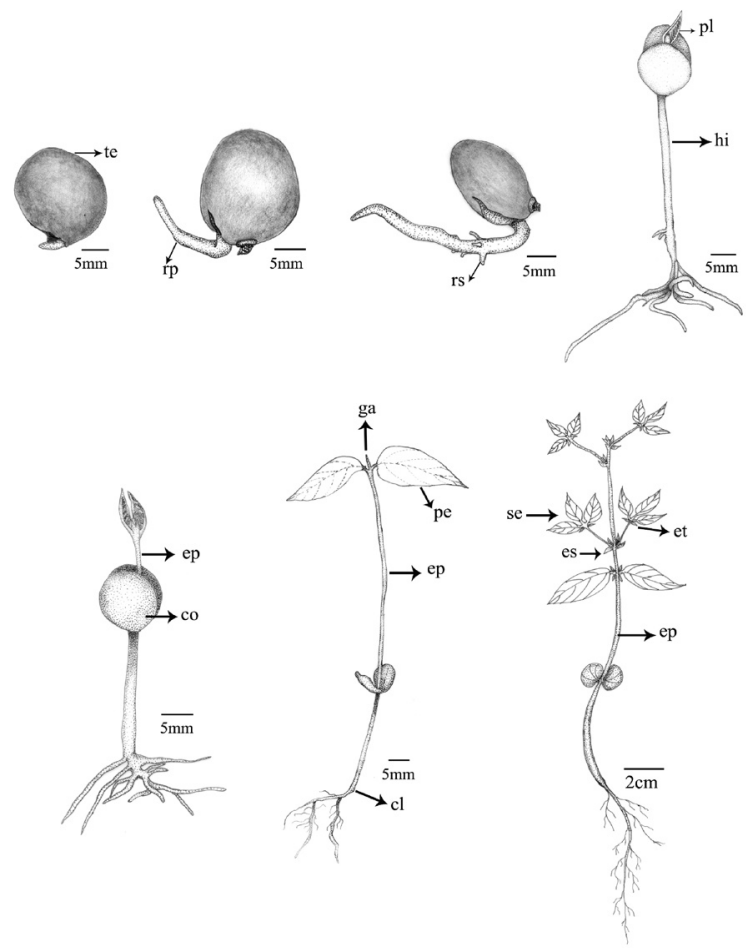

\section{FIGURA 4. Fases do desenvolvimento pós-seminal de Clitoria fairchildiana R.A. Howard.}

Legenda: rp - raiz primária, rs - raiz secundária, hi - hipocótilo, ep epicótilo, co - cotilédone, ga - gema ápice, es - estípula, pe - primeiro par de eófilo, cl - colo, et - estipela, se - segundo par de eófilo).

O epicótilo alonga-se e, em seguida, observa-se a expansão dos eófilos, simples, com forma oblonga, ápice acuminado, inserção oposta, nervuras pinadas e evidentes adaxialmente, com tricomas simples e esparsos, pecíolos curtos, levemente espessados e com estípulas na base. Posteriormente ao desenvolvimento do eófilos, ocorre a formação do segundo par de folhas, compostas trifolioladas, com inserção alterna, com folíolos de ápice acuminados, forma oblonga e com estipelas na base (Figura 4). De acordo 
com Meisenhelder (1969), as primeiras folhas verdadeiras de algumas espécies podem diferir das suas folhas definitivas.

De acordo com Barroso et al. (1984), as leguminosas apresentam o indumento constituído de pêlos simples, unisseriados ou multisseriados, ou de tricomas glandulares. Para Clitoria, Barroso et al. (1984) relatam a presença de estípulas nos folíolos.

\section{CONCLUSÃO}

Os estudos morfológicos envolvendo a unidade de dispersão, a germinação, o crescimento inicial de Clitoria fairchildiana, podem contribuir para o conhecimento do ciclo biológico, da regeneração natural e do manejo e conservação dessa espécie.

As sementes de Clitoria fairchildiana são exalbuminosas, de forma orbicular e achatada, com tegumento de coloração castanho-esverdeada. O hilo tem forma elíptica, homocromo e de tamanho pequeno em relação à semente. Os cotilédones são livres, de coloração verde, maciços e plano-convexos e o embrião é invaginado. O início do desenvolvimento pós-seminal é marcado pelo rompimento do tegumento e emissão da raiz primária, glabra, de coloração amarelo-esverdeada e de forma cilíndrica.

\section{REFERÊNCIAS}

AMORIM, I. L.; DADIVE, A. C.; CHAVES, M. M. F. Morfologia do fruto e da semente, e germinação da semente de Trema micrantha (L.) Blum. Cerne, v. 3, n. 1, p. 138-152, 1997.

ARAÚJO, S. S.; MATOS, V. P. Morfologia da semente e de plântulas de Cassia fistula L. Revista Árvore, v. 15, n. 3, p. 217-223. 1991.

BARROSO, G.M.; PEIXOTO, A.L.; COSTA, C.G.; ICHASO,C.L.F.; GUIMARÃES, E.F.; LIMA, H.C. Sistemática de angiospermas do Brasil, Viçosa: UFV, 1984. v. $2,377 \mathrm{p}$.

BARROSO, G.M.; MORIN, M.P.; PEIXOTO, A.L.; ICHASO,C.L.F. Frutos e sementes - morfologia aplicada à sistemática de dicotiledôneas. Viçosa: UFV, 1999. 443p.

BENINCASA, M.M.P. Análise de crescimento de plantas: noções básicas. Jaboticabal : UNESP, 1988. 41p.

BRASIL.. Ministério da Agricultura e Reforma Agrária. Brasília - DF. Regras para análise de sementes. Brasília, DF, 1992. 365p.

CARNEIRO, M.A.C.; SIQUEIRA, J.O.; MOREIRA,
F.M.S; CARVALHO, D.; BOTELHO, S.A. JUNIOR, O.J.S. Micorriza arbuscular em espécies arbóreas e arbustivas de ocorrência no sudeste do Brasil. Cerne, v. 4, n.1, p.129-145, 1998.

CORNER, E.J.H. The seeds of dicotyledons. Cambrige: University Press, 1976. v.1, 311p.

CRUZ, E. D.; MARTINS, F. de O.; CARVALHO, J. E. U.Biometria de frutos e sementes de jatobá-curuba (Hymenaea intermedia Ducke, Leguminosae Caesalpinioideae). Revista Brasileira de Botânica, v. 24, p. 161-165, 2001.

DAMIÃO-FILHO, C.F. Morfologia e anatomia de sementes. Jaboticabal: FCAV/UNESP, $1993.145 p$. Apostila da disciplina do Curso Pós-graduação Morfologia e Anatomia de Sementes.

DAMIÃO-FILHO, C.F ; MÔRO, F.V. Morfologia Vegetal. 2.ed. Jaboticabal: FUNEP, 2005. 172p.

DUCKE, A.. Notas sobre a flora neotrópica: as leguminosas da Amazônia Brasileira. [S.1.]: Instituto Agronômico do Norte, 1949. 248p. (Instituto Agronômico do Norte. Boletim Técnico, 18).

DUCKE, A.; BLACK, G. A. Notas sobre a fitogeografia da Amazônia brasileira. Boletim Técnico Instituto Agronômico Norte, v.29, p.1-69, 1953.

DUKE, J.A. On tropical tree seedlings. Seed, seedlings, systems and systematics. Annals of Missouri Botanical Gardens, v.56, n.2, p.125-161, 1969.

FELICIANO, A.L.P. Estudo da germinação de sementes e desenvolvimento da muda, acompanhado de descrições morfológicas de 10 espécies arbóreas ocorrentes no semiárido nordestino. 1989. 114f. Dissertação (Mestrado)Universidade Federal de Viçosa, Viçosa.

FORTES, J.L.O. Reabilitação de depósito de rejeito de refino de bauxita com uso de resíduos industriais e leguminosas arbóreas. 2000. 184f. Tese (Doutorado) - Universidade Federal Rural do Rio de Janeiro, Rio de Janeiro.

GROTH, D. ; LIBERAL, O.H.T. Catálogo de identificação de sementes. Campinas: Fundação Cargil, 182p. 1988.

GUAJARÁ, M.; CARVALHO, A.G.; SANTOS, W.; GONÇALVES, K. Aspectos da Biologia de Euphalerus clitoriae Burckhardt \& Guajará, 2000 (Hemiptera: Psyllidae) sob Condições de Campo. Floresta e Ambiente, v.10, p.6975, 2003.

GUNN, C.R. Seed topography in the Fabaceae. Seed Science \& Technology, n. 9, p. 737-757, 1981. 
KUNIYOSHI,Y.S. Morfologia da semente e da germinação de 25 espécies arbóreas de uma floresta com araucária. 1983. 233f. Dissertação (Mestrado) - Universidade Federal do Paraná, Curitiba.

LORENZI, H. Árvores brasileiras: manual de identificação e cultivo de plantas arbóreas nativas do Brasil. Nova Odessa: Plantarum, 1992. 352p.

MAISENHELDER, L.C. Identifying juvenile seedlings in Southern Hardwood forests. New Orleans: Southern Forest Service, $1969.77 \mathrm{p}$.

OLIVEIRA, E. C.; PEREIRA, T.S. Morfologia dos frutos alados em Leguminosae-Caesalpinioideae-Martiodendron Gleason, Peltophorum (Vogel) Walpers, Sclerolobium Vogel, Tachigalia aublet e Schizolobium Vogel. Rodriguesia, v.36, n. 60, p. 35-42, 1984.

OLIVEIRA, A.N.; QUEIROZ, M.S.M.; RAMOS, M.B.P. Estudo morfológico de frutos e sementes de Tefrósia (Tephrosia candica DC. - PAPILIONOIDEAE) na Amazônia Central. Revista Brasileira de Sementes, v. 22, n. 2, p.193199, 2000.

OLIVEIRA, E.C. 1993. Morfologia de plântulas florestais. In: AGUIAR, I. B.; PIÑA-RODRIGUES, F.C.M.; FIGLIOLIA, M.B. (Ed.). Sementes florestais tropicais. Brasília, DF: ABRATES, 1993. p.175-214

OLIVEIRA, D.M.T. Morfologia de plântulas e plantas jovens de 30 espécies arbóreas de Leguminosae. Acta Botanica
Brasílica, v. 13, p. 263-269, 1999.

PAULA, J.E.; ALVES, J.L.H.. Madeiras nativas: anatomia, dendrologia, dendrometria, produção e uso. Brasília, DF: Fundação Mokiti Okada - MOA, 1997. 543 p.

PINHEIRO, A.L.; RAMALHO, R.S.; VIDAL, W.N.; VIDAL, M.R.R. Estudos dendrológicos com vistas à regeneração natural de Meliaceae na microrregião de Viçosa. I. Identificação e descrição de dez espécies. Revista Árvore, v. 13, n. 1, p.1-66, 1989.

PORTELA, R.C.Q.; SILVA, I.L.; PIÑA-RODRIGUES, F.C.M. Crescimento inicial de mudas de Clitoria fairchildiana Howard e Peltophorum dubium (Spreng.) Taub. em diferentes condições de sombreamento. Ciência Florestal, v. 11, n. 2, p. 163-170, 2001.

RIBEIRO, J.E.L.S.; HOPKINS, M.J.G; VICENTINI, A.; SOTHERS, C.A.; COSTA, M.A.S.; BRITO, J.M.; SOUZA, M.A.D.; MARTINS, L.H.P.; LOHMANN, L.G.; ASSUNÇÃO, P.A.C.; PEREIRA, E.C.; SILVA, C.F.; MESQUITA, M.R.; PROCÓPIO, L.C. Flora da reserva Ducke: guia de identificação das plantas vasculares de uma floresta de terra-firma na Amazônia Central. Manuas : INPA, 1999. 816p.

ZANON, A.; CARPANEZZI, A.A.; FOWLER, J.A.P. Germinação em laboratório e armazenamento de sementes de Tarumã-Branco (Citharexylum myrianthum Cham.). Boletim de Pesquisa Florestal, Colombo, n. 35, p.75-82, 1997. 